\title{
Applicability of a Warm-Up Technique in Teaching Sight Translation for Novice Translators: A Case Study
}

\author{
Gailan Mahmood Hussein
}

Department of English, College of Arts, University of Tikrit, Tikrit, Iraq Email: gailan83@tu.edu.iq

\begin{abstract}
This study investigates the warm-up technique applied in teaching sight translation (SiT) through which the confidence of novice translators is underpinned as they start learning how to sight translate. This technique consists of three rungs adopted from Haddad's Model for teaching interpreting, through which the student translators will improve their translation skills by mastering the three stages respectively. To apply such techniques, student translators' performance is improved remarkably by enhancing their self-confidence to manage the translation task successfully and overcoming the faltering on the first phase of the translation task. The students of second year / Department of Translation / College of Arts / University of Tikrit ( 2017-2018) have been used as samples in this study to assess their performance as they sight translate two selected journalistic texts by using a statistical T-test to elicit the variances of their performance. The pre-test was conducted at the beginning of the course, then this technique followed in teaching sight translation. Finally, a posttest was conducted to assess the progress of their performance.
\end{abstract}

Keywords: Sight Translation, Warm-up Techniques, Novice Translators, Pedagogy, Performance.

\section{Introduction}

Teaching translation is not simply realized by random methods and techniques since it requires different skills employed by the students especially when they are still at the first stages of learning. Whether in interpreting or translation, the students must be trained very well to translate properly by finding appropriate equivalents as they interpret/ translate into the source language ( SL).

Generally speaking, Translation is the interpretation of a source text( ST) meaning and the production of an equivalent text meaning in the target language ( TL). Translation is a process that deals with meaning across language barriers. Catford $(1965,20)$ defines translation as "the replacement of textual material in one language (SL) by equivalent material in another language (TL)". In this perspective, the main aim of the translation or interpreting is to find an equivalent of the ST meaning to fit the TT meaning and produce a clear product for the reader or listener respectively. 
In this study, SiT which lies in between translation and interpreting is regarded as a reformulation of the written text into oral product. SiT is a hybrid type represented by translation as a ST and interpreting as a TT, and it requires an intensive training to improve the students' skills for managing it properly. Seeing a ST for the first time necessitates expanding students' knowledge, skimming skills and excellent public speaking to enable them to grasp the meaning of ST by inference the meaning in TT. As the students start experiencing SiT, they will face difficulties in rendering ST. Building on that, teacher of SiT must go on to clarify and use a comprehensive teaching method to train the students to face such difficulties and to strengthen their confidence in managing this type of translation.

Recently, SiT has always been regarded as an exercise of effective communication. Unquestionably, this exercise requires more and more rehearsal of translators to accomplish different translation tasks as effectively and efficiently as possible because it lies between two different modes of translation written translation and or communication or interpreting. Translator training in SiT has thus received an entire attention in training institutions all over the world but it was not enough unless it is applied in teaching in real situation to see into what extent these guidelines can lead in improving the student's performance. The aim of this study is to provide a clear overview of using warm-up technique in teaching SiT for the novice translators and to what extent this technique is beneficial to student translators in enhancing their performance and strengthening their confidence as they sight translate.

\section{Sight Translation ( SiT)}

At the beginning of prominence of the translation studies, most of translation and interpreting scholars did not pay attention to this type of translation and it was neglected until 1990s especially the translation studies bibliographies like TSB (John Benjamins), TSAO (St. Jerome), AIIC Bibliography on Interpreting and CIRIN (A research Bulletin established by Daniel Gile) do not contain too much information on SiT. Then it was noticed that SiT is important to be used in different working environments, as well as it is regarded as a basic step in the ladder of learning interpreting through which the translator is prepared to different modes of interpreting because it necessitates the student translators to improve their language skills for the next steps.

In the field of translation, various definitions of $\mathrm{SiT}$ are found. It has been defined by many scholars as a process of rendering a written text into oral product. This definition simply exemplifies the nature of this type of translation where it lies in the translation studies. SiT is considered as a hybrid mode of translation which lies in between translation and interpreting according to the written ST and oral TT. This 
type of translation requires good understanding and wide knowledge in both languages in order to give an acceptable production of the ST.

For Shuttleworth and Cowie ( 1997:154) sight translation indicates to an unprepared process of oral rendering for a written source text and in which a summary of the ST content is provided taking into consideration the giving of a clear message in TT. Lambert (2004:45) argues that SiT is mediated between translation and interpreting, and this intermediacy makes it as a specific type of written translation as well as a variant of oral interpretation.

In other words, Sadkhan( 2014:9) explains that SiT is carried out in three stages starting with (sight reading) when the interpreter reads with his eyes the SL written text, then (comprehension) as s/he translates it with her/his mind, finally (delivering) as s/he orally renders this written text into the TL. It is a process of oral translation of a written ST in which the input is visual processed by a translator to generate an oral product in TL.

While Zheng et al. (2013:4) emphasizes that SiT comprises the substitution of a message written in one language into a message delivered orally in another language which demands the synchronization of reading and production.

\section{Modes of Sight Translation}

$\mathrm{SiT}$ is normally conducted to produce an oral message which is rendered from a written source message taking into account clarifying the expressions. As a translation process, the written text is viewed by the sight translator to anticipate and find an appropriate equivalent by processing the meaning directly or with support of the dictionaries, finally the target message is uttered aurally. This process requires two basic steps ( perception and production) in which SiT is performed regardless of the environment. Figure ( 1 ) coined by most scholars and researchers who are interested in teaching and studying SiT agree that this type of translation is divided to certain modes according to the way in which it is conducted. The difficulty of these modes are varied in particular degree of complexity. In fact, SiT requires an activation process for the mental operations, in which linguistic and cognitive skills work together to produce a final output.

Ivars(1999: 188-301)explains that there are different modes of SiT which vary according to its complexity and the way in which they are conducted. These modes are: 
Text visually Processing

Supported by dictionaries

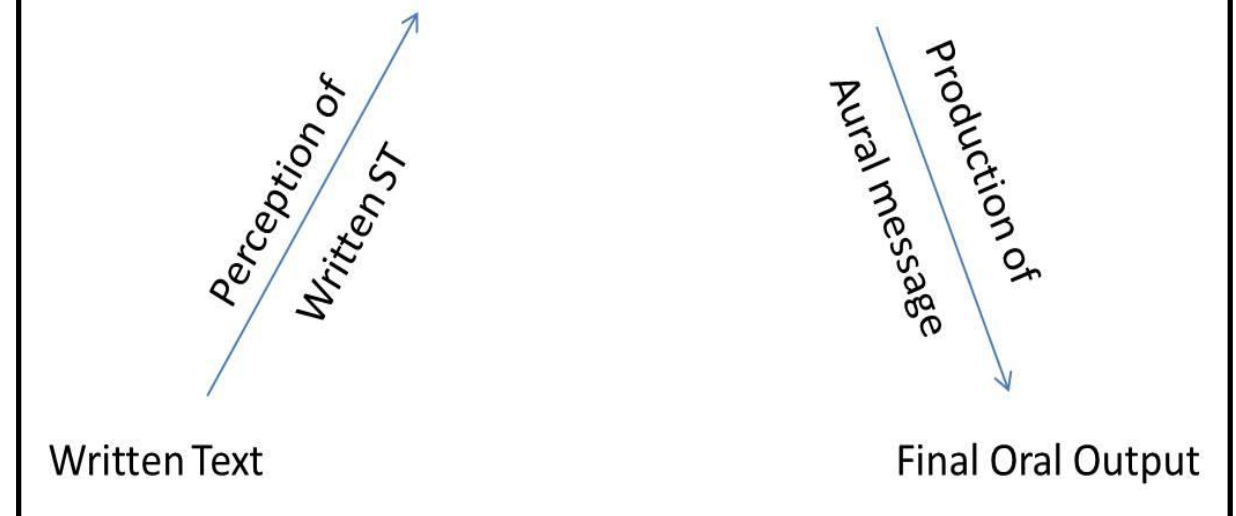

Figure(1): Sight Translation process

1. Proper SiT: This mode is manifested by translation of a written text seen at the first time, and there is no time given for the translator to prepare.

2. Prepared SiT: This mode is easier than the first because the translator will have enough time to translate with enough preparation.

3. Consecutive SiT: In this mode, summary translation is used through which a translation is given for a written text briefly. This mode is regarded in between sight translation and sight interpreting.

4. SiT in Consecutive Interpreting: It is a process of an oral reformulation of a written input which is immediately and loudly uttered by the speaker.

5. SiT in simultaneous interpreting with text: This mode is considered as the most complex because it is a conducted by simultaneous interpreting and sight translation of a written text. This mode can be done when the translator/ interpreter possess a copy of the written text.

\section{Teaching of SiT}

Teaching SiT is an important aspect taken into account by most scholars of translation studies and they put a significant emphasis and effort on the teaching methods because of its importance in preparing the novice translators for more complex process. SiT plays a crucial role in improving the novice translators' skills for a more complex cognitive process through which their language skills are improved for the next interpreting tasks which are highly related with SiT. All scholars agree up on teaching SiT very early stages of translation training programs. Also the curriculum designers of translation programs have agreed to consider SiT as a basic stone of learning and teaching interpreting because of the importance skills employed in such type of translation which are considered crucial for novice 
translators and interpreters. For this reason, SiT is regarded a transformational mode between translation and interpretation because it is mediated between oral and written translation.

Ilg and Lambert( 1996:5) confirm that teaching SiT must be introduced at the early stages of teaching interpreting by giving the students simplified written texts to be rendered into the verbal messages easily. They put SiT in the first step of the teaching interpreting programs in order to enhance the student's performance and increase their confidence in managing such process and giving a clear message.

In this aspect, Kim ( 2001: 8) views SiT as an intermediate step for interpreting students before they initiate the training for consecutive interpreting and simultaneous interpreting. Moreover, SiT is regarded as a teaching tool for training other types of interpreting, because in which the translators will master basic skills needed in the next steps of interpreting to overcome translation difficulties.

According to Sampaio ( 2007, cited in Sadkhan:2014:13-14) teaching SiT must be done according to a model which reflects the learning and teaching processes and certain criteria which are related to the teaching method of this type of translation that requires a comprehension of the ST, clarity of ideas, degree of hesitations, capacity of student's production of TT.

Morin ( 2007:3) provides a comprehensive assessment of student's performance, accuracy, clarity, fluency, eye contact and self-confidence. He asserts that the fourth and fifth items ( eye contact and self-confidence) are highly related with student's psychological aspects, and this assessment is to be conducted on a daily basis according the program outlines determined by the curriculum designers.

While Elamin (2008: 17) states that SiT can be taught at the beginning of translation programs in order to prepare for more complex processes. It is given in short paragraphs which gradually complicated in order to familiarize the students with difficulties they face according to the text type. She explains that teaching SiT in successive steps help the students to improve their oral expression skills and linguistic knowledge.

On the other hand, Hale ( 2007: 15) explains that there are two teaching methods in which there are two key role for delivering SiT: Memory and Comprehension. Both of them are required in each teaching method in order to master this process. Memory is critical to retrieve the meaning by relying on short-term memory and long-term memory while comprehension is a cognitive- oriented process that starts when the translator reads the ST to find an appropriate meaning for TT. 
For Lee (2012:4) the teaching context, views, content, aims and ideas, and course organization principles, all of which are vital components in systematic course design, have not received much attention. Therefore, it is crucial to develop an effective pedagogical approach to enhance novice translators' performance.

\section{Skills needed by Novice Translators in SiT.}

In General, Translation requires exceptional skills to be performed properly and correctly in rendering the ST into TT. The novice translators need to master specific skills which help them to sight translate ST into oral output sufficiently and adequately. The skillset of such type of translation must be adapted by novice translators because they are considered the backbone of their performance scale and prepare them for the next interpreting modes in which their confidence will be strengthen.

In sight translation, there are many skills which are regarded as a must to perform this type of translation confidently. Reading and speaking skills are basic skills to be master perfectly because the time of reading the text refers to the translator's cognitive ability in managing the text and analyzing it in a very limited time frame. Reading has also been regarded a useful skill in developing novice translators' oral skills and language-transfer skills through the process of reformulating the ST into the TT.

Regarding reading skills, Nickerson (1981: 273) states that the average English speakers speak at a rate of between 125 words and 175 words per minute. Individual speech rate and performance stylishness differences may explain individual variances, focused more on precise rendition than on delivery time. Such different configurations may influence the quality of SiT performances.

For Samuelsson-Brown( 2004:2) the translation skills in a cluster through which students can master translation properly in order to render understood message for the recipients. The cluster below shows the most important skills that the novice translators need to perform in the translation process. To work as a translator, these skills must be learned perfectly to reach well understood and meaningful message in the SL. Figure (2) shows the cluster of translation skills required by the novice translator. 


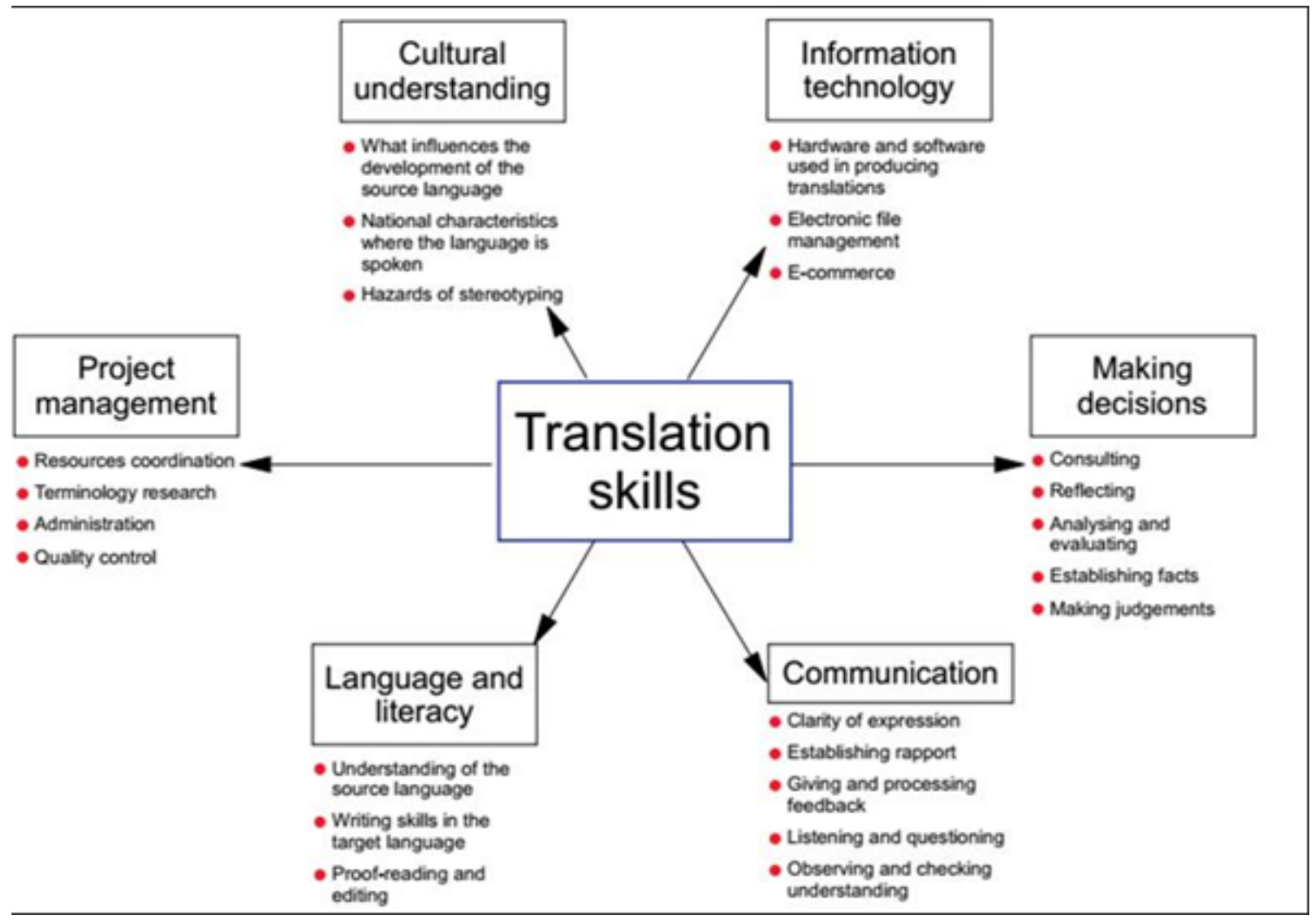

Figure (2) Translation Skills Cluster

In this perspective, $\mathrm{Wu}(2010: 35)$ emphasizes that there are many key skills that a translator must possess in order to perform his/her task efficaciously. These skills as follows:

1. Having a wide variety of expressions in the SL and TL.

2. Being a competent in grammar, morphology of both languages.

3. Possessing a comprehensive knowledge of both languages.

4. Being faithful in rendering the original thought and ideas.

5. Being patient because translation requires a period of time of practice and training.

SiT has received a considerable scholarly attention in recent years, Sadkhan (ibid:22) mentions that sight translators need to master some skills in SiT in order to cope the translational difficulties in such type of translation. SiT requires to some extent translation skills in to be able managing the process perfectly and correctly. To sight translate, the novice translators will be required to understand these skills in details and how to encounter the translation difficulties they may face when during SiT process. The following skills are very important during SiT: 
1. Practicing conceptual reflexes to understand the idea quickly.

2. Instantaneous memory exercises to translate the same ideas.

3. Understanding a text in its whole not word-by-word.

4. Sentence visualization.

5. Enrichment of vocabulary of the texts.

6. Finding an appropriate synonym.

7. Clarity of thought.

8. Ability to sustain a constant level of concentration.

9. Finding a balance between the language reading and speaking skills

The abovementioned skills are very important for the novice sight translators to improve their competence and performance as they sight translate. These skills will increase their self-confidence gradually to perform such type of translation which requires a high level of attention and cognitive capabilities. These skills have an impact on the teaching method of SiT as the novice translators start their SiT courses in order to be familiarized with this new mode of translation that requires a comprehensive knowledge and ability. All these perquisites will improve their language skills for more difficult context of interpreting because SiT is taught in the first step of interpreting ladder to rehabilitate them for interpreting modes such as consecutive interpreting and simultaneous interpreting.

\section{Warm - Up Technique in Teaching SiT.}

In this paper, the impact of applicability of warm-up technique has been taken into consideration by the researcher and applied it in teaching SiT. This technique has three rungs that are applied in teaching SiT for novice translators and see to what extent this technique is very important and effective in improving their selfconfidence gradually. This techniques has been adopted from Haddad's model of teaching interpreting (Confidence Building-Strategies).

Haddad (2006: 32-33) classifies this technique into three phases (three rungs) which are organized according to their difficulties in order to make the students familiarized with these difficulties gradually. The first phase is the least difficulty in this technique in order to decrease the stress of failure the novice translators expect as they initiate SiT.

In this context, Haddad (ibid) emphasizes that this technique is regarded as a perquisite of the interpreting students because it has a vital impact in improving their self-confidence for interpreting process ( CI and SI) because SiT lies in between translation in interpreting, as well as through such technique the novice translators will reinforce their knowledge step by step to overcome the translation difficulties. 
Moreover, Haddad(2008: 5) states that this technique includes physical presence of the ST and disappearance of technical interpreting devices and equipment, which support the novice translator to feel more comfortable and confident in the next phases of interpreting by strengthening their confidence gradually. The effectiveness of the warm-up technique has been reflected and applied in teaching SiT according the rungs suggested by Haddad which played very decisive role to improve the students' performance. This technique is divided as follows:

\section{Warm-up technique ( Rung1):}

In this rung, the students are provided with both ST and TT, then they are guided to read both of them quickly ( approximately 10 minutes). Guide the students to sight translate without looking at the target text. The students will be introduced into a vocabulary of ST which help them to know the strange words, as well as this step will simplify the next translation task and increase their self-confidence.

\section{Warm-up technique ( Rung 2):}

In this rung, The students are not given the TT, but they are allowed to use their dictionaries before they sight translate and they are advised to depend on their memories by not writing an translated word on the paper.

\section{Warm-up technique ( rung 3):}

In this rung, the students are not allowed to access into dictionaries only instructed to identify the main verb of each sentence in the ST and read aloud to sight translate in a shorter time than the first two rungs.

\section{Experimental Field of Study.}

This aspect of the study focuses on the analysis of the pre-test and post-test of the students' performance and how it is analyzed according to the statistical T-test. Basically, this technique has be used in teaching SiT at the beginning of the course after the conducting the pretest which was done according to the tradition method used by most instructors in teaching SiT. The rungs of the technique have been followed precisely in teaching such type after the pre-test. This means that when such a technique is used in teaching SiT which requires a highly attention with good cognitive processing for the ST that leads to improve the students' performance and self-confidence to render ST clearly and perfectly. Appendix (A) represents the data collected from students' performance during pre-test and post-test.

\subsection{Pre-Test Analysis.}

This test has been conducted before using this technique in teaching SiT to see the individual variances of each student according to the traditional teaching method. 
This method is followed by many instructors in teaching such type of translation without taking into account how to help the students in enhancing their performance by certain steps and strengthen their confidence. The traditional technique does not give the students opportunity to overcome the difficulties the face as they sight translate. Below the data of this pre-test of four weeks have been analyzed by T-test so as to find the mean .

$$
\mathrm{X} 1+\mathrm{X} 2+\mathrm{X} 3+\mathrm{X} 4 \ldots \ldots+\mathrm{X} 20
$$

Mean $=$

Table (1) Mean of the Pre-test

\begin{tabular}{|c|c|c|c|c|}
\hline Weeks of Pre-test & Week1 & Week2 & Week3 & Week4 \\
\hline Mean & 4.2 & 4.6 & 4.9 & 5.1 \\
\hline
\end{tabular}

In this Table (1), the mean of students' performance for four weeks refers that the students have no knowledge how to manage such type of translation because their performance was generally unsatisfied. During the first week the mean was 4.2 which the lowest value during the pre-test, this is regarded to their lack of background knowledge of how to manage SiT process. The students are considered as novice translators, therefore they need certain course of training in SiT and to improve their self-confidence.

The mean clarifies that their performance is improved gradually but it was promising because there was very slight increasing in the value of their performance. The means the students have tried to manage the ST sufficiently but they were highly hesitated because of lack of self-confidence that they will give a wrong translation for ST. The students suffered from a degree of cognitive stress and were unable to manage such new type of translation which requires certain degree of training due to specific training program.

The last week of the pre-test was 5.1 which regarded as promising step towards a sort of improving their confidence to perform SiT which requires good skills. Moreover, self-training and memory practices are vital tools to support the skills of the students because self-training supports the students to practice SiT individually and prepare them for more difficult stages. While the memory is very important to recall the meaning of the words they translate. This also requires course of training for their memory especially short-term memory. 
In brief, this pre-test shows that the students' performance development which requires more attention and a perfect teaching method to improve their performance and enhance their self-confidence in managing such type of translation.

\subsection{Post-Test Analysis.}

The post-test has been conducted after applying warm-up technique in teaching SiT. This test has mean of the students' performance during four weeks. The values indicate to a significant progress of the students' performance because of the technique applied step by step to teaching the students how to strengthen their confidence in SiT.

Table (2) Mean of the Pre-test

\begin{tabular}{|c|r|c|c|c|}
\hline Weeks of Pre-test & Week1 & Week2 & Week3 & Week4 \\
\hline Mean & 6.6 & 6.8 & 7.1 & 7.8 \\
\hline
\end{tabular}

In Table (2) the mean shows a positive results after applying this technique in teaching SiT because of the most important aspects the students learned to follow in each rung of this technique and to what extent they are important to improve their skills supported by a highly awareness of enhancing their confidence based on confidence-building strategies in teaching interpreting. This technique is part of the these strategies in preparing the novice translator for more difficult interpreting tasks ( CI and SI) respectively.

The rungs of the warm-up technique have an effective impact in the results of this pre-test because each rung has its own importance in teaching SiT. Rung (1) is the first step taken in this technique in order to familiarize the students with nature of such type of translation and how to manage it with the physical presence of the ST and TT. This rung has a psychological effect on students because they feel more comfortable as they read the TT to have an idea of the context of the sentence and how the TT is rearranged to give a clear message in TL.

The results are likely to be related to the performance of the students during Rung (2) of the post-test in which the students use their dictionaries with a limited use and depend on their memory more than dictionaries. In this rung, they are advised to avoid dictionaries because they will consume time looking for the meaning of the words they need. Their memory plays vital role in retrieval the meaning because they work a wide repertoire of vocabularies in different contexts. Moreover, this rung is more complex than the rung (1) because there is no translation for the TT and it requires a unique technique to manage it supported by a good memory training. 
The effect of applying this technique appeared in the last two week because in Rung ( 3 ) the student's confidence is highly recognized in their performance. When the students sight translate the ST loudly without dictionaries and give them a short time.

Additionally, they are guided to identify the main verb in every sentence. The availability of the ST help the students to boost their confidence significantly in Rung(3) which is clearly reflected in the mean values of the third and fourth weeks (7.1) and (7.8) respectively. The post-test proves that applying such technique in teaching SiT has an effective implication to reach positive results that can be reflected in the results of both tests. Generally speaking, this technique plays very pedagogical step in preparing the students for more difficult task on the ladder of interpreting and making them perform such complicated task to done by novice translators confidently.

\section{Conclusion.}

Warm-up technique is a new teaching method applied in teaching SiT as a part of confidence-build strategies. The two test showed a clear difference in the values of each week where the students perform sight translation. Teaching SiT according to the traditional method is not useful because the students are not accustomed with it because it needs a highly cognitive processing for the ST and find the proper equivalents in TT. Applying these three rungs are considered as a pedagogical tool for improving the student's performance and to support their self-confidence in learning such type of translation which lies as a hybrid mode in between translation and interpreting.

The progress in the results revealed that the students as novice translators need an instructive teaching method to depend on taking into account the impact of their memory to back-up their performance in rendering the ST. Since the availability of the ST, they need to enrich their vocabularies capacity to find the equivalent directly and to overcome the language barriers confidently. These rungs help the novice translators to prepare for more difficult interpreting processes ( $\mathrm{CI}$ and $\mathrm{SI}$ ) respectively.

According to the results of the both tests, the researcher highly recommends all lecturers and curriculum designers to take into account such theoretical impact and its direct effect on teaching such type of translation. This technique is applied perfectly to teach SiT according the results showed in the data elicited from the students' performance. This technique proves that rungs give a wide knowledge for the student in managing such hybrid mode which requires a good skillset. 


\section{Reference}

1. Catford, J.C. (1965) A Linguistic Theory of Translation. Oxford: OUP

2. Elamin, S.(2008).Sight Translation: its methods and techniques, and its use for developing translation skills: University of Khartoum, Adab Journal of Faculty of Arts, Vol.26,DEC.2008.

3. Haddad, S. ( 2008). "Training Interpreters: Not Easy Task", Damascus University Journal, Vol.24 No.1+2, 2008.

4. Haddad, S. (2006). Interpreting: Confidence-Building Strategies. Damascus: Damascus University Publications.

5. Hale, S.B (2007). Community Interpreting. Hampshire, UK: Palgrave Macmillan.

6. Ilg, G. and Lambert, S. (1996). "Teaching Consecutive Interpreting", Interpreting: Vol. 1(1), 1996.pp.69-99.

7. Ivars, A. (1999). Translation At Sight a Descriptive Analysis: Published MA Thesis : Universitat Jaume.

8. Kim, C.(2001). Sight Translation in its own Right. Published MA Thesis: California State University.

9. Lambert, S. (2004), "Shared Attention during Sight Translation, Sight Interpretation and Simultaneous Interpretation". Meta, Vol. 49, No.294-306.

10. Lee, J.(2012).What Skills Do Student Interpreters Need to Learn in Sight Translation Training?. Meta, 57(3), 694-714.

11. Mark, S. and Moria, Cowie. (1997).Dictionary of Translation Studies. London: Rutledge.

12. Morin, I. (2007). " Six Phases in Teaching Sight Interpretation". Translation Journal . Vol. 11,No.2.

13. Nickerson, R. (1981): Speech understanding and reading: Some differences and similarities. In: Ovid J. L. Tzeng and Harry Singer, eds. From Perception of Print: Reading Research in Experimental Psychology. Hillsdale: Lawrence Erlbaum Associates.

14. Sadkhan, R.(2014). Sight Translation: Practical Lessons: Al-Ghadeer Co. for Printing and Publications Ltd.

15. Sampaio, G.R.L( 2007). Assessing Reading Fluency. Hawaii: Pacific Resources for Educational and Learning.

16. Samuelsson-Brown, G. (2004). A Practical Guide for Translators.Uk: Multilingual Matters Ltd.

17. Wu, Shao-Chuan (2010).Assessing Simultaneous Interpreting. Newcastle: Newcastle University. 
18. Zheng, et al. (2013) 'Processing metaphorical expressions in sight translation : an empirical-experimental research.', Babel., 59 (2). pp. 160-183.

تطبيق تقتية الاحماء في تدريس الترجمة البصرية للمترجمين المبتدئين: دراسة حالة

الملخص

تتحرى هذه الدراسة تقنيات الاحماء المتبعة في تدريس التزجمة البصرية لفرض دعم ثقة الطلبة المبتدئين عندما يبلأ يتعلموز كيفية الترجمة بصريـاً. تتكوز هذه التقنيات من ثلاث مراحل تم تبنيها من انموذج حداد لتدريس الترجمة الشفوية فهن خلاله يستطيع الطلبة المترجمين تطوير مهاراتهه عز طريق اتقان هذه المراحل على التوالي. و بتطبيق هذه التقنيات فان مهارة المترجميز من الطلبة ستتحسن بشكل ملحوظ عز طريق تعزيز ثتتهم بـأنقسهم في ادارة هذه المهمة بشكل ناجع و التفلب على التردد الحاصل في الطور الاول خلال عملية الترجمة. تم استخلم طلبة المرحلة الثانية / قسم الترجمة/ كلية الآداب / جامعة تكريت للسنة الدراسية ( 2017- 2018 ) كنماذج للاختبار لتقييم ادائهم في ترجمة نصين صحفيين بصرياً بـاستخدام اختبار- تي الاحصائي واستخراج الفروق الفردية. حيث تم تنفيذ الاختبار القبلي في بلداية الفصل الدراسي و بعدها تم اتباع هذه التقنيات في تدريس الترجمة البصرية و بالنهاية تم تنفيذ الاختبار البعدي لتقييم التقدم الحاصل في ادائهم.

Appendix (A): Scores of Students' Performance

\begin{tabular}{|c|c|c|c|c|c|c|c|c|}
\hline \multicolumn{4}{|c|}{ Post-test } & \multicolumn{4}{|c|}{ Pre-test } & \multirow[t]{2}{*}{ Samples } \\
\hline $\begin{array}{r}\text { Week } \\
4 \\
\end{array}$ & Week3 & Week2 & Week 1 & $\begin{array}{r}\text { Week } \\
4 \\
\end{array}$ & $\begin{array}{r}\text { Week } \\
3 \\
\end{array}$ & $\begin{array}{r}\text { Week } \\
2 \\
\end{array}$ & Week 1 & \\
\hline 8 & 6 & 7 & 6 & 5 & 4 & 2 & 3 & Sample1 \\
\hline 7 & 7 & 7 & 5 & 4 & 5 & 2 & 3 & Sample2 \\
\hline 8 & 7 & 5 & 6 & 6 & 5 & 5 & 1 & Sample3 \\
\hline 7 & 6 & 6 & 6 & 4 & 5 & 3 & 2 & Sample4 \\
\hline 6 & 7 & 8 & 7 & 5 & 6 & 4 & 5 & Sample5 \\
\hline 8 & 7 & 7 & 9 & 6 & 7 & 5 & 8 & Sample6 \\
\hline 8 & 7 & 6 & 8 & 6 & 6 & 4 & 3 & Sample7 \\
\hline 7 & 7 & 7 & 6 & 5 & 5 & 5 & 6 & Sample8 \\
\hline 8 & 8 & 9 & 7 & 5 & 6 & 4 & 5 & Sample9 \\
\hline 6 & 7 & 5 & 6 & 4 & 4 & 5 & 3 & Sample10 \\
\hline 9 & 8 & 7 & 8 & 6 & 4 & 6 & 6 & Sample11 \\
\hline 7 & 6 & 8 & 6 & 7 & 6 & 5 & 4 & Sample12 \\
\hline 8 & 6 & 9 & 7 & 6 & 5 & 7 & 5 & Sample13 \\
\hline 9 & 8 & 6 & 6 & 5 & 6 & 5 & 4 & Sample14 \\
\hline 8 & 7 & 6 & 7 & 5 & 6 & 6 & 6 & Sample15 \\
\hline 8 & 7 & 8 & 6 & 5 & 3 & 4 & 5 & Sample16 \\
\hline 8 & 8 & 7 & 7 & 6 & 3 & 6 & 5 & Sample17 \\
\hline 8 & 7 & 5 & 7 & 5 & 5 & 4 & 3 & Sample18 \\
\hline 9 & 8 & 8 & 6 & 6 & 5 & 5 & 4 & Sample19 \\
\hline 9 & 8 & 6 & 7 & 4 & 3 & 5 & 3 & Sample20 \\
\hline
\end{tabular}

